\title{
Tardive dyskinesia: screening and risk disclosure
}

\author{
Robert Chaplin and Mark Potter
}

\begin{abstract}
A questionnaire was sent to a random sample of 339 psychicitists on the Royal College mailing list, enquiring about their practice of screening and risk disclosure in patients of itsk of tardive dyskinesta. The response rate was 70\%. There was wide variation in the rate of informing patients of the risk. Over hatf of the respondents felt that knowledge obout tardive dyskinesla would reduce compliance, a viow which precticted a low rate of informing patients. There was support for the bsuing of clinical proctice guidelines by the College. Psychiatriats need further ectucation about tardlve dyskinesia.
\end{abstract}

The risk of tardive dyskinesia complicating antipsychotic treatment is well established. Kane et al (1984) reported an incidence of $3-4 \%$ of patients per year receiving new prescriptions, indicating tardive dyskinesia may complicate relatively short-term treatment. The prevalence is $20 \%$ of patients receiving long-term prescriptions (Woerner et al, 1991).

In the USA, most states have statutory policies concerning disclosure of risk of antipsychotics. The American Psychiatric Association has issued guidelines for screening practices and methods of obtaining informed consent to treatment and some centres operate local policies for management of tardive dyskinesia. However, a postal questionnaire study found clinicians needed educating about the prevention of tardive dyskdnesia (Benjamin \& Munetz, 1994). The situation in Britain is very different with neither statutory policies nor clinical guidelines covering disclosure of the risk of tardive dyskinesia. This study investigates the practice of screening and risk disclosure of tardive dyskinesia among British psychiatrists.

\section{The study}

A nine item, self-administered questionnaire was adapted from that developed by Benjamin \& Munetz (1994) for use in Britain. The areas covered were the existence of a tardive dyskinesia monitoring policy. the frequency of and staff responsible for screening, personal experience of litigation, the extent to which patients are informed about tardive dyskinesia and views about formal policies for screening and risk disclosure.

The questionnaire received approval by the Royal College of Psychiatrists' Research Committee, was piloted by psychiatrists locally and sent on three occasions to a random sample of psychiatrists on the College mailing list. These included College members and inceptors, but excluded those belonging to special interest groups in child and adolescent psychiatry, psychotherapy and drug and alcohol use. It was anonymous although the respondents were asked to state their age. gender and regional health authority.

\section{Findings}

Two hundred and thirty-eight (70\%) questionnaires were returned and a total of $221(65 \%)$ were filled out correctly. Respondents had a mean age of 42 (range 25-65); 69\% were male, and represented all regions of Britain. With regard to speciality, $55 \%$ indicated they practised general psychiatry, $22 \%$ old age, $12 \%$ learning disabilities, $6 \%$ forensic and $4 \%$ child and adolescent.

They were asked about screening practices for patients at risk of tardive dyskinesia. A regular screening interval was given by $45 \%$ of respondents but only $4 \%$ stated their service had a formalised screening policy. Medical staff performed the majority of assessments and were aided by community psychiatric nurses in the services of $53 \%$ of respondents. Other mental health professionals only rarely took part. The assessment of tardive dyskinesia was most commonly performed by observation of the patient ( $94 \%$ of replies), included a medical examination in only $35 \%$ of replies and the use of a structured instrument (e.g. the Abnormal Involuntary Movements Scale; AIMS; Guy, 1976) in $5 \%$.

Litigation had personally been experienced by only one respondent, a further $12 \%$ knew of litigation involving other clinicians but the majority $(65 \%)$ were concerned about possible litigation by patients with tardive dyskinesia. There was support for the development of guidelines by the Royal College of Psychiatrists from $74 \%$ of respondents, for local guidelines from $26 \%$, but only $4 \%$ supported statutory 
regulations for screening. management and risk disclosure of tardive dyskinesia.

The respondents were asked how many patients they warned about the risk of tardive dyskinesta (Table 1). Those who said they informed $25 \%$ or less of their patients were more likely to be female psychiatrists $(P=0.03)$, or specialising in old age rather than in general psychiatry $(P=0.004)$, but no less likely to be concerned about litigation $(P=0.6)$. The seniority or geographical location of practice of the psychiatrist was not significantly associated with willingness to inform. They were asked to indicate whether they agreed with the statement 'Disclosure of the risk of tardive dyskinesia is harmful as it causes non-compliance with medication and increased relapse risk.' The $55 \%$ who indicated that they agreed were significantly more likely to state a low rate ( $25 \%$ or less) of informing patients of risk ( $P=0.004)$.

Those respondents who indicated that they did not routinely inform patients of the risk of tardive dyskinesia were asked to state why. Of the $\mathbf{7 0}$ who replied, the most frequent reasons were fear of non-compliance (32 responses), inability to give informed consent (8 responses) and discussion occurring with relatives instead (8 responses). More surprising responses cited were the rarity of tardive dyskinesia (10 responses), the decision to treat with antipsychotics was made by another clinician (6 responses), lack of time, forgetfulness, the issue was 'not of importance in the elderly', and 'most patients are not bothered' (one response each).

Seventy-six respondents provided general comments. Common themes were supported for risk disclosure policy guidelines, disclosure of risk to be based on an individual risk-benefit analysis, informed consent to antipsychotic treatment would help compliance, and complaints by junior staff about lack of guidance.

\section{Comment}

Psychiatrists lack agreement in their practises of screening and risk disclosure to patients at risk of

Table 1. Psychiatrists' estimation of the percentage of their patients they inform about the risk of tardive dyskinesia

\begin{tabular}{lc}
\hline $\begin{array}{l}\text { Percentoge of patients informed } \\
\text { cbout the risk of tardive dyskinesia }\end{array}$ & Responses \\
\hline All patients at risk & $34(15 \%)$ \\
$75 \%$ of patients at risk & $52(23 \%)$ \\
$50 \%$ of patients at risk & $24(11 \%)$ \\
$25 \%$ of patients at risk & $62(28 \%)$ \\
Never inform patients & $20(9 \%)$ \\
Don't know & $29(13 \%)$ \\
Total & 221 \\
\hline
\end{tabular}

developing tardive dyskinesia. They seldom medically examine or assess regularly for the condition and almost never use standardised assessments. Although most respondents were concerned about the risk of litigation, only one respondent had personally experienced it. This is further supported by enquiries to the main medical defence organisations who were unaware of any tardive dyskinesia related litigation. Surprisingly, concern or knowledge about litigation did not result in respondents informing more patients of the risk.

This study shows a reluctance to discuss this disabling condition, the most commonly cited reason being fear of non-compliance with medication and relapse. Common law governs real consent to informal treatment and the Sidaway case (BMJ Legal Correspondent, 1985) upheld the right of doctors to withhold information about side-effects of treatment, also called therapeutic privilege. Hence doctors may choose not to disclose a risk if they believe it would be detrimental to a patient's health and it appears that not informing patients about tardive dyskdnesia could be justified by this principle.

There is evidence though that informing patients of the risks of antipsychotic treatment does not reduce compliance or harm their mental health and results in an increased knowledge about their treatment (Kleinman et al, 1989). It also results in less reporting of side-effects (Brown et al, 1987) possibly due to patients feeling less anxious about them. Additionally, as the principle of informed consent is supported in the Department of Health's 1993 Code of Practice of the Mental Health Act 1983, it appears difficult to justify the withholding of information from patients on grounds of feared non-compliance.

There is a need for psychiatrists to reach agreement about informing patients at risk. This could be achieved by clinical practice guidelines or a consensus statement and would recetve support from most respondents. Detection of the condition could be improved by the training of non-medical staff in the assessment of patients (Munetz \& Benjamin, 1990). Some psychiatrists continue to hold views about tardive dyskinesia that are not supported by current literature, for example the condition being rare, and are in need of continuing education. More research is needed into the risks and benefits of informing patients about tardive dyskinesia.

\section{Acknowledgements}

The authors would like to thank the respondents for completing the questionnaire and Lundbeck for their research donation. 


\section{References}

BenJamin, S. \& MUNETZ, M. R. (1994) Community mental health centre practices related to tardive dyskinesla screening and informed consent for neuroleptic drugs. Hospital and Community Psychiatry. 46. 343-346.

BRTISH MEDICAL JOURNAL LEGAL CORRESPONDENT (1985) What should a doctor tell. British Medical Journal, 290. 780-781.

BRoWN, C. S., WRIGHT, R. G. \& Christensen, D. B. (1987) Association between type of medication instruction and patient's knowledge. side-effects and compliance. Hospital and Community Psychiatry. 38, 55-60.

DePartment OF Health AND Welsh Office (1993) Code of Practice 1993: Mental Health Act 1983. London: HMSO.

GuY. W. (1976) ECDEU Assessment Manual for Psychopathology. Washington, DC: US Department of Health. Education and Welfare.
KANE, J. M., WOERNER, M., WEINHOLD, P., et al (1984) Incidence of tardive dyskinesia: Five year data from a prospective study. Psychopharmacology Bulletin, 20, 387-389.

KLEINMAN, I., SCHACHTER, D. \& KORTAR, E. (1989) Informed consent and tardive dyskinesia. American Journal of Psychiatry. 146. 902-904.

MUNETZ, M. R. \& BENUAMIN, S. (1990) Who should perform the AIMS examination. Hospital and Community Psychiatry. 41, 912-915.

Woerner, M., KANE, J. M., LEBerman, et al (1991) The prevalence of tardive dyskinesia. Journal of Clinical Psychopharmacology, 11, 34-42.

*Robert Chaplin, and Mark Potter, Department of Mental Health Sciences, St George's Hospital Medical School, Cranmer Terrace, London SW17 ORE

*Correspondence

\section{$£$ Seminars in Clinical Psychopharmacology Edited by David J. King}

Psychopharmacology is a key both to the understanding of the biological basis of severe mental illness and to the rational use of drugs in clinical psychiatry. This book is an excellent introduction to an ever-expanding and fascinating subject, linking relevant basic neuropharmacology to clinical practice. It aims to bridge the gap between the theoretical basis for the mode of action of psychotropic drugs and guidance on their clinical use, and should increase interest in and understanding of the drugs widely used in clinical practice. $£ 20.00,544 p p ., 1995$, ISBN 0902241737

Available from bookshops and from the Publications Department, Royal College of Psychiatrists, 17 Belgrave Square, London SW1X 8PG (Tel. 01712352351 extension 146) 